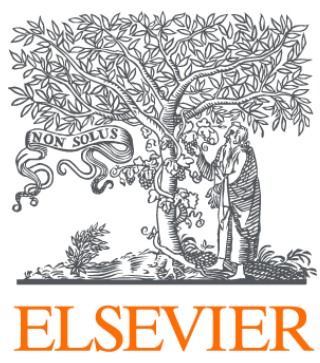

Since January 2020 Elsevier has created a COVID-19 resource centre with free information in English and Mandarin on the novel coronavirus COVID-

19. The COVID-19 resource centre is hosted on Elsevier Connect, the company's public news and information website.

Elsevier hereby grants permission to make all its COVID-19-related research that is available on the COVID-19 resource centre - including this research content - immediately available in PubMed Central and other publicly funded repositories, such as the WHO COVID database with rights for unrestricted research re-use and analyses in any form or by any means with acknowledgement of the original source. These permissions are granted for free by Elsevier for as long as the COVID-19 resource centre remains active. 


\title{
Pneumomediastinum Related to Covid-19 Pneumonia
}

\author{
Nicola Romano, $\mathrm{MD}^{1, *}$, Aldo Fischetti, $\mathrm{MD}^{1}$ and \\ Enrico Francesco Melani, MD ${ }^{2}$ \\ ${ }^{1}$ Department of Area Radiologica, Ente Ospedaliero Ospedali Galliera, Genoa, Italy; ${ }^{2}$ Department of Radiology, Ente Ospedaliero Ospedali Gal- \\ liera, Genoa, Italy *(E-mail: romano.nicola@live.it). \\ Funding statement: This research did not receive any specific grant from funding agencies in the public, commercial, or not-for-profit sectors. \\ Conflict of interest statement: The authors have no personal, financial, or institutional interest with regards to the authorship and/or publication of this \\ manuscript.
}

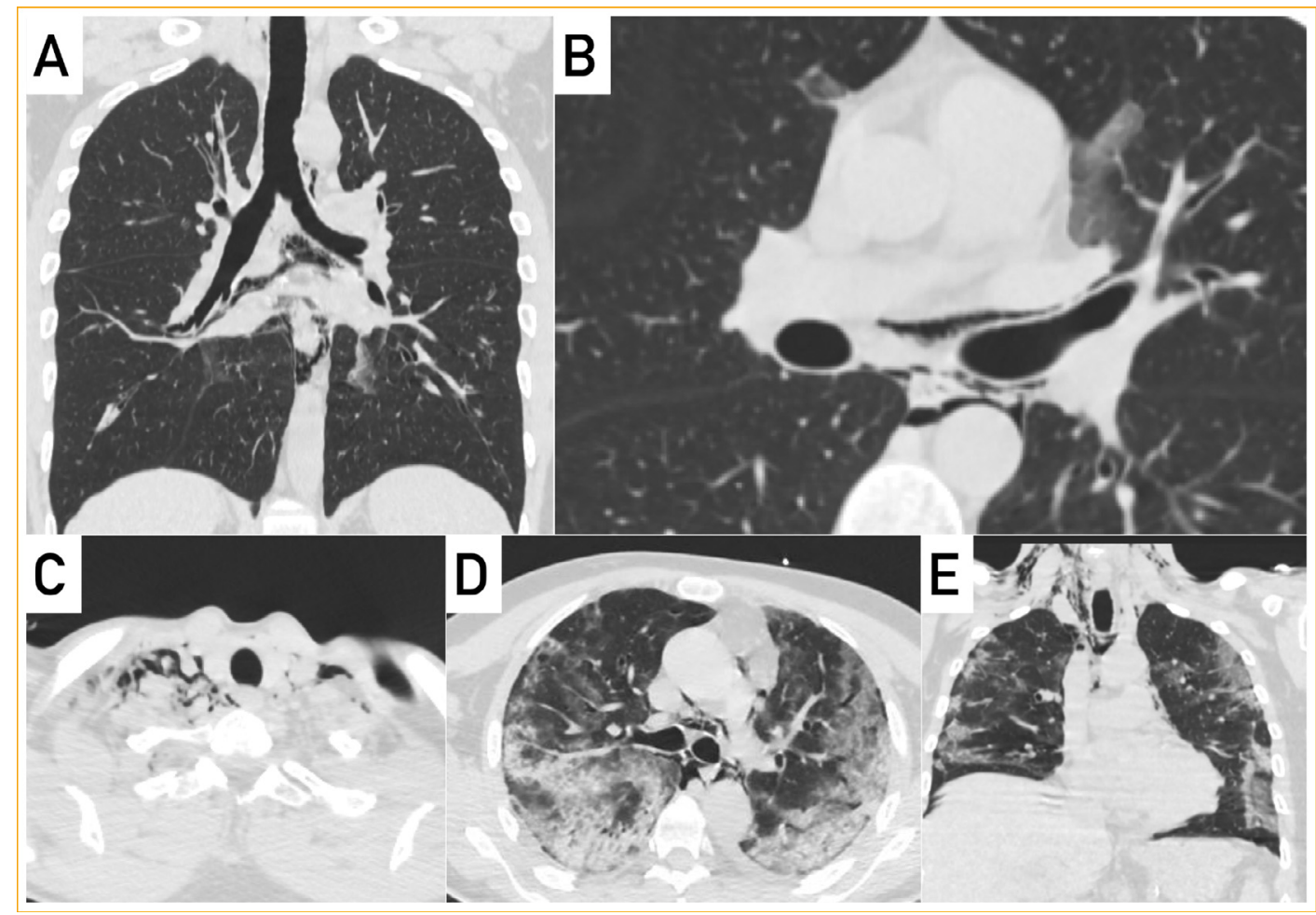

FIGURE.

\section{CASE PRESENTATION}

$\mathrm{n}$ March 2020, during the pandemic scenario of the new coronavirus, named Severe Acute Respiratory Syndrome Coronavirus 2 related to the novel viral pneumonia consequently named Covid-19 (Coronavirus Disease 2019), several chest computed tomography (CT) scans were performed in suspected cases to evaluate pulmonary involvement and stage the disease. At the same time, scientific papers have illustrated the most common radiological features of the Covid-19 pneumonia: multifocal bilateral peripheral ground glass areas and subsegmental patchy consolidations with subpleural location and predominant involvement of lower lung lobes and posterior segments. In this context, among the different patterns and findings described, the presence of pneumomediastinum was rarely reported in literature, ${ }^{1-3}$ and rarely considered in scientific debates. We herein report two cases of pneumomediastinum related to Covid-19 pneumonia, in patients who underwent chest-CT scan in our Hospital. The first patient was a 30year-old male, who complained of fever $\left(37.6^{\circ}\right)$ and dyspnea with wheezing sounds at auscultation. Laboratory tests showed elevated leukocytes ( 13,180 cells per $\mu \mathrm{L})$ with $13,4 \%$ of lymphocytes; C-reactive protein was mildly elevated (3.26 mg/L). Unenhanced chest CT-scan revealed the presence of some small ground-glass opacities bilaterally, in particular in para-cardiac regions of superior and inferior lobes, findings compatible with Covid-19 pneumonia. Surprisingly, an amount of free air bubbles was present in the superficial cervical soft tissue (around sternocleidomastoid muscles and thyroid gland) and descending into the mediastinal cavity (around trachea, esophagus and great vessels; Figure A, B). The second patient underwent a follow-up CT 2 weeks later 
that showed resolution of the pneumomediastinum. The second patient was a 65-year-old male, presented to emergency complaining of severe dyspnea, with associated low oxygen saturation and fever. Complete blood count showed elevated leukocytes (23,710 cells per $\mu \mathrm{L}$ ) with only $6.6 \%$ of lymphocytes; elevation of C-reactive protein $(4.01 \mathrm{mg} / \mathrm{dL})$, lactate dehydrogenase $(627 \mu / \mathrm{L})$, glutamic-oxaloacetic transaminase $(57 \mu / L)$ and glutamic-pyruvic transaminase $(154 \mu / \mathrm{L})$ was also present. Unenhanced chest CT-scan (partially influenced by respiratory motion artifacts) demonstrated bilateral areas of ground-glass opacity and consolidations diffused bilaterally in pulmonary lobes, features compatible with the suspicion of Covid-19 pneumonia; also in this case, an abundant pneumomediastinum was present, associated with cervical soft-tissue emphysema (Figure C-E). Nasopharyngeal swab test for Covid-19 confirmed infection and the followup CT done 2 weeks later demonstrated the complete resolution of pneumomediastinum and soft tissue emphysema. As known, a spontaneous pneumomediastinum may be caused by a pressure gradient between the alveoli and pulmonary interstitium leading to alveolar breakdown as described by Macklin. ${ }^{4}$ In cases of infection by
SARS-CoV, pneumomediastinum may be related to damage and rupture of alveolar membrane caused by the virus. ${ }^{3,5}$ Although pneumomediastinum is usually considered a self-limiting condition, with an unknown precise pathological mechanism, we wanted to describe this possible complication of Covid-19 pneumonia, that may be considered a potential indicator of worsening disease. ${ }^{1}$

\section{AUTHOR CONTRIBUTIONS}

$\mathrm{NR}, \mathrm{AF}$ and EFM wrote the text; NR prepared figures; $\mathrm{NR}, \mathrm{AF}$ and EFM approved the final manuscript.

\section{REFERENCES}

1. Zhou C, Gao C, Xie Y, et al. COVID-19 with spontaneous pneumomediastinum. Lancet Infect Dis. 2020;20(4):510.

2. Sun R, Liu H, Wang X. Mediastinal emphysema, giant bulla, and pneumothorax developed during the course of Covid-19 pneumonia. Korean $J$ Radiol. 2020;21(5):541-544.

3. Kolani S, Nawfal H, Haloua M, et al. Spontaneous pneumomediastinum occurring in the SARS-COV-2 infection. IDCases. 2020;21:e00806.

4. Macia I, Moya J, Ramos R, et al. Spontaneous pneumomediastinum: 41 cases. Eur J Cardiothorac Surg. 2007;31(6):1110-1114.

5. Gralinski LE, Baric RS. Molecular pathology of emerging coronavirus infections. J Pathol. 2015;235(2):185-195. 